\title{
Entrevista a Susana Novaro, directora de la asociación civil Idas y Vueltas
}

\section{Gerardo Ribero' y Emilia Firpo Reggio²}

DOI: https://doi.org/10.37125/ISR.7.1.14

Susana Novaro es la actual directora de la asociación civil Idas y Vueltas. Recuerda con entusiasmo sus primeras participaciones en la temática de las migraciones; allá por la década del ochenta, cuando estaba «recién recibida». Fue, nos contó, en un proyecto organizado por Amnistía Internacional, el Instituto de Estudios Legales y Sociales del Uruguay (Ielsur) y el Servicio Paz y Justicia (Serpaj), donde se encargaba de la elegibilidad de las personas que solicitaban refugio en nuestro país. Se trataba en su mayoría de ciudadanos colombianos, migrados por motivos políticos, durante el período de represión y "genocidio político»³ de la Unión Patriótica. Y ciudadanos chilenos expulsados de la universidad durante la dictadura de Augusto Pinochet.

Participó activamente en la redacción de la Ley n. ${ }^{\circ} 18.076$ de Derecho al Refugio y a los Refugiados (Uruguay, 2006) y se mantuvo ligada a la Comisión para los Refugiados desde entonces.

La coyuntura de la que emergió la migración dominicana a Uruguay marcó el momento de sus primeras aproximaciones a Idas y Vueltas. Finalmente, el año 2018 marca el momento de su incorporación definitiva a la asociación como integrante de la comisión directiva.

Cuando Susana se aparecía —o al menos durante el tiempo prepandemia-, por la asociación, termo y mate de por medio, saludaba muy fraternalmente a las personas que a menudo se encontraban en la sede de la asociación. El día elegido eran los sábados, en los que Susana intentaba a través del buen trato y la cordialidad propiciar espacios distendidos donde compartir un café «con gusto a café».

Susana nos cuenta que su anhelo respecto de la asociación es que pueda mejorar los vínculos con todos los actores involucrados. Ampliar y fortalecer los lazos con la Universidad de la República (Udelar) mediante la participación en la medicina,

1 Departamento de Territorio, Ambiente y Paisaje del Centro Universitario Regional del Este. gerardoribero@gmail.com

2 Núcleo de Estudios Migratorios y Movimientos de Población, Facultad de Humanidades y ciencias de la Educación, Universidad de la República.

$3 \mathrm{Al}$ menos así lo definió el Centro Nacional de Memoria Histórica (2018), como genocidio de la fuerza política entre 1984 y 2002, que dejó, por lo menos, 4153 personas asesinadas, secuestradas o desaparecidas (Sepúlveda, 2018). 
por ejemplo. Como sucede en países europeos, en los que existe, desde hace mucho tiempo, la medicina intercultural. En cuanto a las relaciones con el Estado, sueña con políticas realmente receptivas a la migración, a los refugiados y a los solicitantes de refugio. Reclama mejores lugares para la incidencia, en los que se tengan espacios donde esté más claro cómo y cuándo expresar el mensaje de la asociación.

\section{Idas y Vueltas y la Universidad de la República}

Son múltiples los espacios y actividades en las que la asociación participa junto a la Udelar en diversos proyectos en su gran mayoría de extensión. Le preguntamos a Susana acerca del vínculo que tiene con nuestra casa de estudios.

\section{¿Cómo se forió el lazo con la Facultad de Humanidades y la Udelar?}

Susana: Inicialmente los primeros acercamientos tuvieron que ver con las clases de español para extranjeros. Para nosotros es fundamental porque es el sustento teórico, es la mirada académica sobre los fenómenos que estamos atravesando a diario. Un análisis que es externo e interno, porque muchos de ellos forman parte de la institución, permite otra mirada, un poco más externa y a la vez más valiosa. Porque lo que aporta es el conocimiento teórico, que nosotros no tenemos. Si nos quedamos solo con el derecho internacional de refugiados, el derecho internacional humanitario es mucho más limitado de lo que nos puede aportar la gente de antropología. Es como la mirada externa de los flujos migratorios. Es sumamente valioso cuando miramos nuestras prácticas, el análisis permanente de la práctica en temas de discriminación, racismo. Siempre la mirada crítica la ha dado la universidad.

\section{En ese contacto íntimo que tiene con la Udelar, ¿̇cómo evalúan esa relación de cara a los desafíos de los próximos años?}

S: La Universidad, como en todo, ha estado muy abierta al fenómeno migratorio, de hecho, hemos incorporado en Facultad de Enfermería el curso de Enfermería Intercultural. Existen muchos ámbitos en los que la problemática ha sido tratada. La universidad lo ha tomado como suyo. Pero por ejemplo en Relaciones Internacionales [carrera que se ofrece en la Facultad de Derecho, de la Udelar] sigue sin tener una materia sobre migraciones, sobre derecho internacional de las migraciones. Tenía algo, apenas sobre derecho internacional de refugiados. Me llamaron para corregir una tesis y a otros funcionarios. Ha sido un fenómeno desconocido, sin embargo, la universidad lo ha tomado con interés. Cancillería ha intentado hacer una vinculación con mayor voluntad de cumplir con las convenciones. 
Especialmente, con la Ley n. ${ }^{\circ} 18.250$, [Ley de Migraciones (Uruguay, 2008)], que tiene una voluntad de cumplir las convenciones, sobre todo para la protección de los derechos de los trabajadores migrantes y sus familias. Este es el gran desafío del siglo Xxi: hacer que los derechos se cumplan fuera del país de origen.

\section{Los que andan a las Idas y Vueltas}

\section{¿En qué condiciones llegan y qué respuestas reciben las personas que se arriman a Idas y Vueltas?}

S: Lo que uno trata de hacer es buscar caminos de salida con el mayor respeto. Promover la integración a través del acceso a los distintos derechos. Lo primero que un migrante tiene que conseguir es la regularización migratoria. Existe un núcleo de población, concretamente los cubanos, haitianos, dominicanos a quienes se les exige visa. Esas personas cuando llegan a la frontera como no tienen visa, acuden a la protección internacional; solicitan refugio, y por esa vía entran. Se trata del corrimiento de un problema migratorio hacia el terreno de la protección internacional. En vez de solucionar un problema migratorio con un procedimiento migratorio se permite un ingreso con una solicitud que no es lo más adecuado para dicho ingreso. Luego el proceso de regularización migratoria exige que esas personas tengan que desplazarse dentro de frontera, ir a consulados y solicitar la visa. Todo eso requiere un asesoramiento y una orientación que son necesarios. Lo que hay que garantizar es que, durante todo ese proceso, esas personas subsistan, porque esa población que llega, no viene con ahorros, no es una población acomodada, es gente que viene a trabajar. Necesitan sí o sí trabajar porque normalmente no tienen para comer al día siguiente. Todo eso tiene una carga emocional muy importante, por eso se busca en Idas y Vueltas que las instancias de los sábados sean lo más distendidas posible. Se busca que sean espacios donde puedan alejarse de su situación cotidiana, tener un encuentro que sea lúdico, que participen, que jueguen, de algo más distendido, baile, música, canto que se yo, otras cosas. Si bien siempre está presente esa sobra de otras cosas que hay que resolver.

\section{Hay un aprendizaje personal \\ en el trabajo que ustedes hacen cotidianamente con personas migrantes. ¿Cómo ven ese aprendizaje?}

S: Lleva mucho trabajo, mucha observación y mucha crítica, ver y analizar si la práctica es la conveniente o no, si es el camino adecuado o no. Y cuáles pueden ser las necesidades futuras, qué cosas sería positivo y contrastarlas con ellos. Por ejemplo, Muchos de nosotros cuando nos acercamos a la asociación decimos «Sería fantástico que salieran de las pensiones que salieran de ese lugar de hacinamiento, horrible». 
Pero, después de trabajar, nos damos cuenta de que es una aspiración nuestra; hay gente a la que le gusta vivir ahí porque tiene una compañía, un ejercicio de sociabilidad. Tiene un espacio que comparte con los demás. Tienen un montón de cosas que Nosotros no las vemos, y quizá se trata de mejorar las condiciones, y tal vez no sea un mal sistema, no intento defender las pensiones en sí, pero a veces hay que contrastar con la realidad que ellos plantean. Las nuestras son ideas preconcebidas y que no siempre concuerda con la realidad.

\section{Idas y Vueltas tiene una oficina en Chuy que trabaja con migrantes que ingresan por la frontera entre Brasil y Uruguay. ¿ Cómo opera la asociación concretamente en la frontera?}

S: Hay dos compañeros trabajando, un antropólogo y una asistente social que tienen mucho trabajo. Reciben muchas personas que necesitan asesoramiento. Parte de su trabajo es participar de todas las reuniones con las autoridades locales. Hay mesas en las que se junta el MIDEs [Ministerio de Desarrollo Social], Asse [Administración de los Servicios de Salud del Estado], socat [Servicios de Orientación, Consulta y Articulación Territorial], el municipio y se buscan soluciones. Esto hace que su trabajo sea muy pesado. Porque una cosa son las situaciones concretas de las personas que acaban de llegar o que todavía no llegaron al país; en su paso previo al ingreso a la oficina de migraciones. Allí se tienen que hacer el hisopado y luego son derivados a ASSE. Los compañeros están siempre trabajando con estas realidades complejas.

La comunicación con estos funcionarios se hace de forma permanente. Utilizamos los recursos que están en Montevideo para los casos de personas en la frontera.

\section{¿Compartís la idea de que el Estado se ha descansado en los esfuerzos que hace la sociedad civil para abordar el problema de las migraciones?}

S: Yo creo que sí, creo que sí. Creo que, además, cada vez más los cambios de gobierno en este sentido no han sido propicios. Hay como un desentendimiento, nos dicen: «De esto que se hagan cargo los organismos internacionales, ustedes dicen que esto es así, háganse cargo»; no explícitamente, pero es así.

Un ejemplo de esto podría ser un punto de información educativa en el MEC [Ministerio de Educación y Cultura], que sería necesario que se replicara en el MIDEs. Hay una necesidad que la información se replique en otros lugares. La mejor manera de que las personas se integren cuanto antes es recibiendo la mayor información posible. Y esta información no tiene la difusión necesaria. La afiliación a Asse fue una lucha que costó mucho. Cuando la tramitación de la cédula llegaba a demorar un año, un año y pico, era importante que estuvieran afiliados a ASSE y nos costó mucho, al final se logró. 
La clave es que se sienten bien, respetados, bien tratados. Creo que eso hace que exista una simbiosis, que se sientan bien, y todo fluya respetando las reglas de la casa. Eso hace al éxito, obviamente.

\section{¿Cuáles han sido los desafíos que han tenido que enfrentar en este mundo de pandemia y cuáles son los desafíos futuros que deberá afrontar la asociación?}

S: Está muy complicado, ha tenido distintas etapas. Hubo primero una etapa de cierre total de fronteras. Luego se empezaron a abrir solo para las personas que alegaban necesitar protección internacional (solicitantes de refugio). En número fue muy inferior a los del año pasado. En este momento se está volviendo, se ha producido una especie de descentralización en la frontera. Se revisa caso a caso, y se decide en frontera. Y no se admite la solicitud solo en caso de persecución muy fundamentada. En tiempo de pandemia ha habido mucho miedo al otro, miedo a que me traigan la enfermedad. Los altos costos que tienen los insumos hospitalarios han generado un ruido en los puntos de entrada muy delicado. Eso no está solucionado. Es un problema que está instalado en este momento, y no sabemos cómo se va a solucionar. Para solucionar el tema, primero tenemos que ser honestos y saber que cualquier persona a la que se le niega el ingreso en las fronteras, va a ingresar igual. Es fácil negar la entrada si hay un puente o un lugar que no sea fácil pasar. Una frontera que impida verdaderamente el paso. En los casos de fronteras secas son personas que vienen caminando desde Venezuela o Cuba. Entonces no se van a ir porque un funcionario les dé un acta de rechazo. Pero es real que los ingresos se hacen igual. Y es importante el ingreso regular en un lugar donde hay fronteras militarizadas. Y se va a convertir en un bolsón de migrantes. De ninguna manera hago una apología o estoy a favor del ingreso irregular.

Hay fuerzas que no se dominan, una de ellas es la migración. Cuatro millones de venezolanos andan caminando por toda Latinoamérica. Y eso va a seguir sucediendo. Las medidas no son las adecuadas, solamente con la oposición a ese movimiento no hay solución posible para una integración adecuada.

\section{¿En qué lugar se para frente a los desafíos de las derivas de la migración global?}

S: Nosotros defendemos la libertad migratoria. Las personas tienen derecho a elegir el lugar donde entienden que los beneficia y que van a llevar una buena vida. Si las personas están un año o diez años. En ningún momento Idas y Vueltas va a emitir un juicio acerca de dónde van a iniciar una nueva vida. Nosotros no juzgamos. No emitimos juicio sobre el proyecto migratorio. Es un proyecto personal el cual no podemos intervenir. Hasta el día de hoy no hemos visto alteraciones en la migración 
que se presenta en nuestro país. Salvo por las personas que piden visa para irse a Nicaragua. Nosotros sabemos que probablemente se van a ir de ahí a Estados Unidos. Esto no ha afectado los ingresos al país. Uno de los temas en juego con los gobiernos de los países de origen es, por ejemplo, la visa. Que es una exigencia, por ejemplo, de Cuba, y no de Uruguay. Si fuera por Uruguay eliminaba la visa para los cubanos. Incluso los partidos con representación parlamentaria estuvieron de acuerdo con la eliminación de la visa. Todo esto, forma parte de los desafíos del siglo xxi. Lograr que los derechos humanos se cumplan fuera del país de origen. En el siglo xx era en el país de origen y ahora pasamos a que se cumplan fuera del país de origen.

Por eso la Ley de Migraciones (Uruguay, 2008) dispone la creación de organismos como la Junta Nacional de Migraciones, el consejo consultivo y asesor de las migraciones con participación de la sociedad civil. Crea institutos para lograr ese entorno favorable a la migración que buscamos. Sin embargo, en la práctica, después de diez años de vigencia de la ley aún hay muchos hechos que están en solamente en papel. En la práctica no se cumple, siguen existiendo discriminaciones, racismo, xenofobia. Pero... vamos caminando.

\section{Referencias}

Centro Nacional de Memoria Histórica (CNMH) (2018). Todo pasó frente a nuestros ojos. El genocidio de la Unión Patriótica 1984-2002. Bogotá: CNMH.

SEPúlvedA, J. P. (2018, julio 31) «Todo pasó ante nuestros ojos»: claves del informe sobre el exterminio de la UP [Publicación en blog]. En Pacifista! Recuperado de https://pacifista.tv/notas/ todo-paso-ante-nuestros-ojos-claves-del-informe-sobre-el-exterminio-de-la-up/

URUGUay (2006, diciembre 19). Ley n. ${ }^{\circ}$ 18.076: Derecho al Refugio y a los Refugiados. Ley de Refugiados. Recuperado de https://www.impo.com.uy/bases/leyes/18076-2006/14.

URUGuaY (2008, enero 6). Ley n. ${ }^{\circ}$ 18.250: Ley de Migraciones. Recuperado de https://www.impo.com.uy/ bases/leyes/18250-2008/76. 


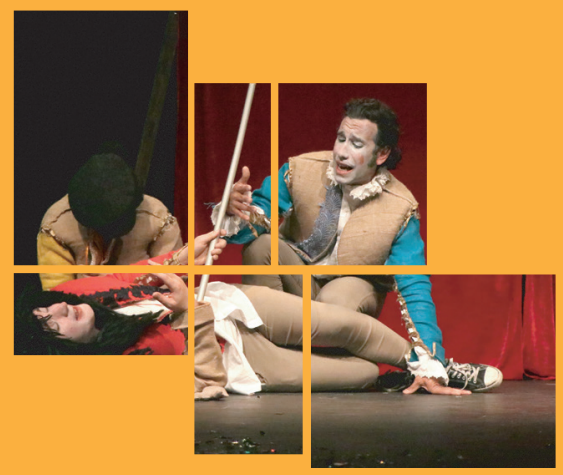

